\title{
Switching to Fully Online EFL Learning Environments: An exploratory study on learners' perceptions
}

\author{
Marco Cancino, Daniel Avila \\ Universidad Andres Bello \\ Correspondence concerning this article should be addressed to Marco Cancino, Department of English \\ Language, Universidad Andres Bello, Fernandez Concha 700, Las Condes, Santiago, Chile. \\ E-mail: marco.cancino@unab.cl
}

\begin{abstract}
One aspect of online classes that has recently experienced a paradigm shift is fully online language environments (FOLEs) - that is, learning settings where $100 \%$ of the content of the class is being delivered online. The SARS-CoV-2 (COVID-19) outbreak in 2020 called for the use of fully online teaching in schools and universities in many countries due to confinement measures. Accordingly, schools have made extraordinary efforts towards implementing homebased schooling and delivered online courses to their students during the pandemic. In many universities, online platforms such as Blackboard Collaborate are being used to fulfil the need to keep up with the requirements of academic programmes. However, research findings addressing specific FOLE platforms are scarce, with even fewer studies focusing on learners' engagement perceptions in those settings. Therefore, the purpose of this mixed-methods exploratory study was to delve into aspects involved in engagement, such as participation, group work, instructional materials, and learning strategies, regarded as key factors influencing the success of FOLEs. Thus, a FOLE questionnaire was administered to 54 EFL university learners, which was followed by semi-structured interviews conducted with seven participants. Our analysis drew from FOLE engagement research (Sun, 2014) and the community of inquiry (CoI) framework (Garrison \& Arbaugh, 2007; Garrison et al., 2000). The main findings revealed that the poor interactions with peers and the lack of peer rapport negatively influenced the social presence of students (Garrison \& Arbaugh, 2007), that the instructor can use teaching presence to increase student awareness of the relevance of the online environment and overcome adaptation issues (Kebritchi et al., 2017), and that teaching presence can help increase cognitive presence and facilitate effective interactions with the content. Implications for pedagogy were put forward as part of a FOLE approach.
\end{abstract}

Keywords: CALL, online language learning, learners' perceptions, engagement, community of inquiry

\section{Introduction}

Since the beginning of the 21st century, many universities have introduced online modalities in the courses they deliver. One aspect of online classes that has recently experienced a paradigm shift is fully online language environments (FOLEs) - that is, learning settings where 100\% of the content of the class is being delivered online (Allen \& Seaman, 2013). This area represents "a distinct field of education that has its own unique and inherent characteristics, significantly different from campus-based education or blended learning" (Wang \& Chen, 2009, p. 4). The SARS-CoV-2 (COVID-19) outbreak in 2020 has called for the use of fully online teaching in schools and universities in many countries due to confinement measures. Accordingly, schools have made extraordinary efforts towards implementing home-based schooling and delivering online courses to their students during the pandemic (Wang et al., 2020). Indeed, the COVID-19 health crisis has placed online learning in the spotlight of educational systems around the world, and the need to understand its effects and its effectiveness has gained relevance accordingly. The pandemic has established differences regarding planned online learning and emergency remote teaching (ERT). Planned online learning involves a well-designed approach to the creation of virtual learning experiences that emerge from careful planning prior to the offering of the course (Schultz \& DeMers, 2020). Hodges et al. (2020) refer to ERT as a temporary change in the way that instruction is delivered due to unforeseen circumstances or crises that requires switching from the previous mode of delivery (i.e., face-to-face) to a fully online environment. They go on to state that the primary goal for 
ERT approaches is to provide this temporary platform where students can receive instruction despite a current crisis, rather than establishing a strong educational foothold from which learning will be delivered in the future. Schultz and DeMers (2020) warn that the hasty implementation of online platforms for reengineered courses does not help to reduce the perceived shortcomings of online teaching when compared to face-to face delivery. Thus, the creation of an effective learning community that is based on improving the quality of interactions between student and content, student and student, and student and instructor, can produce better learning outcomes in online environments (Bernard et al., 2009).

The effectiveness of community for online learning has also been assessed under perspectives that focus on a community of inquiry (CoI; Garrison et al., 2000; Garrison \& Arbaugh, 2007), a framework that addresses the complexities of online learning and highlights the sense of an online community. Garrison et al., (2000) first identified three essential elements for the delivery of a successful online class: social, teaching, and cognitive presence. Social presence refers to "the ability of participants to identify with the community (e.g., course of study), communicate purposefully in a trusting environment, and develop interpersonal relationships by way of projecting their individual personalities" (Garrison, 2009, p. 352). Social presence can help create group cohesiveness and effectiveness, which have been found to correlate with learning achievement (Hwang \& Arbaugh, 2006) and satisfaction with the delivery medium (Arbaugh \& Benbunan-Fich, 2006). Social presence is a necessary variable in the development of cognitive presence, as students who develop social bonds are more intellectually engaged (Garrison \& Arbaugh, 2007). Cognitive presence is defined by Garrison et al. (2000) as "the extent to which the participants in any particular configuration of a community of inquiry are able to construct meaning through sustained communication" (p. 89). Effective cognitive presence involves defining a problem, seeking relevant information, integrating ideas, and testing solutions (Garrison et al., 2010). Finally, teaching presence is defined by Anderson et al. (2001) as 'the design, facilitation and direction of cognitive and social processes for the purpose of realizing personally meaningful and educationally worthwhile learning outcomes' (p. 5). Teaching presence mediates the quality of the interaction being created by the students' social presence. The mere interaction of a learner with other learners or with the content will not ensure effective online learning (Garrison et al., 2000; Garrison \& Arbaugh, 2007). The teacher is the expert who can design attainable parameters for the tasks, facilitate the understanding of learners, and finally instruct them to complete the tasks (Anderson et al., 2001). The community of inquiry framework has been widely used to explore online course effectiveness and has been linked to student satisfaction, engagement, and learning outcomes (Caskurlu et al., 2021; Richardson et al., 2017).

Regarding the background of the study, FOLE courses have been growing and gaining a prominent place in tertiary education systems (Allen \& Seaman, 2018), and in English as a Foreign Language (EFL) contexts (Bañados, 2013). FOLEs have played a relevant role in educational settings, helping educational institutions to reach more learners during the COVID-19 restrictions faced by countries around the world. In many universities, online platforms such as Blackboard Collaborate are used to fulfil the need to keep up with the requirements of academic programmes. However, research addressing specific fully online language learning in platforms such as Zoom or Blackboard Collaborate are scarce, with even fewer studies focusing on learners' engagement perceptions in those settings (Kebritchi et al., 2017; Sun, 2014). FOLEs are gaining relevance in EFL settings such as Chile, where English is extensively used for businesses, education, and technological purposes (Nickerson, 2010). As English is a global language that allows people to share their ideas with a wider population (Crystal, 2006), learning English becomes essential for securing better opportunities in a globalised world. Chile is among the countries that have been making efforts to encourage EFL learning (Author \& Díaz, 2020), which has allowed the country to reach a moderate EFL proficiency level and be ranked 37 out of 100 countries as assessed by the EF English Proficiency Index $(2020)^{1}$. These results make it relevant to explore the attitudes of learners in terms of the difficulties they perceive in fully online EFL learning environments that have been prompted by ERT. Attitudinal components in this respect have been found to be closely associated with learner satisfaction, and consequently with learner achievement (Hodges et al., 2020; Şahin Kızıl, 2020). Therefore, the purpose of this mixed-methods exploratory study was to investigate aspects involved in engagement, such as participation, group work, instructional materials, and learning strategies (Sun, 2014) that are regarded as key factors influencing the success of FOLEs. It must be noted that FOLEs were discussed and analysed as part of an ERT approach. This perspective highlighted the attitudinal differences between the previous mode of

${ }^{1}$ EF Education First (2020). EF English Proficiency Index. https://www.ef.com/wwen/epi/ 


\section{SWITCHING TO FULLY ONLINE EFL LEARNING ENVIRONMENTS}

delivery to which students were exposed (face-to-face) and the current one (FOLE), as well as the difficulties faced by these students in this learning environment. The main research question for the present study is:

What are university EFL learners' perceptions of their engagement towards aspects of their FOLE lessons?

This research question will be tackled from a quantitative perspective (by means of a quantitative questionnaire) and from a qualitative perspective (by means of semi-structured interviews).

\section{Computer Assisted Language Learning (CALL)}

Over the last 15 years, studies have evidenced the rise of the use of online platforms for educational purposes, where regular lessons are adapted in order for students to receive education online. Beatty (2013) defined computer assisted language learning (CALL) as "any process in which a learner uses a computer and, as a result, improves his or her language" (p. 7). CALL approaches share features with computer mediated communication (CMC), which was first defined by Herring $(1996$, p.1) as "communication that takes place between human beings via the instrumentality of a computer." This definition implies that although CMC tools are not specifically intended for learning, they have the potential to do so. Indeed, at the turn of the century, researchers were already arguing that CMC would change socialisation paradigms (Posmes \& Spears, 1998; Thurlow et al., 2004). Furthermore, Yao and Ling (2020) conclude that CMC's impact on human communication forces scholars to rethink human communication at every level.

CALL is embedded in distance education, which occurs when the teaching is being delivered at the same time but from a different place (synchronous distance learning) or at a different time and at a different place (asynchronous distance learning; Dahlstrom-Hakki et al., 2020; Simonson et al, 2019). Allen and Seaman (2013) stated that out of the four types of learning modalities that exist - namely, traditional learning, web-facilitated learning, blended learning, and online learning - three of them make use of distance learning. The authors make use of a body of research based on national reports tracking online education in the United States to differentiate the modalities, which are characterised depending on the proportion of the content that is being delivered online: web-facilitated learning has $1-29 \%$ of the content being delivered online; blended learning has $30-79 \%$ of the content being delivered online; and online learning has $80-100 \%$ of the content being delivered online. Pedagogical adjustments must be made to traditional learning for learners to benefit from distance education tools more efficiently (Hampel \& de los Arcos, 2013). Additionally, teachers must reflect on the necessary skills needed to teach a distance education course. In fact, Hampel and Stickler (2005) argued that teacher training addressing technical skills, and pedagogical adaptations for online teaching must be introduced by institutions that offer courses based on distance education. Similarly, Murphy (2015) stated that instructors must transform their teaching skills in order to deliver a more structured, non-threatening, and inclusive online teaching experience.

The implementation of CALL is not unidimensional, as there are a variety of ways it can be implemented. Beatty (2013) identifies approaches to CALL that can include games, digital media, World Wide Web resources, and major social media platforms such as Facebook or Twitter. A number of studies have been carried out to measure the effects of CALL on language courses. For example, Marzban (2011) reported positive outcomes for the inclusion of CALL in EFL language courses by students who took an EFL reading comprehension instructional course using CALL technologies. These learners outperformed students who were taught the course through a face-to-face modality. Furthermore, teachers regarded the use of CALL in their classes as a highly valued alternative in terms of the functions that it provides to deliver the class (Mei et al., 2018).

\section{Learning Management System (LMSs)}

The platforms in which CALL takes place are known as learning management systems (LMSs), which have become prominent in many educational institutions. An LMS is defined as "the infrastructure that delivers and manages instructional content, identifies and assesses individual and organizational learning or training goals, tracks the progress towards meeting those goals, and collects and presents data for supervising the learning process of an organization as a whole" (Watson \& Watson, 2007; p. 28). Examples of LMSs include Moodle, Edmodo, and Blackboard Collaborate. These platforms can be differentiated in terms of their limitations, efficiency, and overall ideal performance (Cavus, 2013). According to Pella (2014), LMSs are mostly used in higher education, as universities seek to carry out classes and courses through online means. Cavus (2013) also states that the features that an LMS should possess to be considered as such are pedagogical outcomes, a 
learning environment, instructor and administrator tools, course and curriculum design, and technical specifications. Pella (2014) states that LMSs are typically implemented through synchronous communication and additional online programs whereby the instructor or teacher is the expert who delivers the course to the students. Recent studies report that students acknowledge the benefits of LMSs and are willing to enrol in courses that promote them (Raza et al., 2021).

\section{Learner Engagement}

The concept of engagement has attracted growing interest among educational researchers and has been tackled from different perspectives. According to Axelson and Flick (2010), student engagement refers to "how involved or interested students appear to be, and how connected they are to their classes..." (p. 38). Other approaches have underscored the sense of belonging of a student in a learning community, the amount of active and collaborative learning, the involvement in the activities, and the meaningful interactions with teachers (Coates, 2007). Frederick et al. (2004) see engagement as a way to ameliorate school issues such as low levels of academic achievement or high dropout rates in urban areas. They discuss the multifaceted nature of engagement by addressing three main aspects: behavioural, emotional, and cognitive engagement. Behavioural engagement is linked to the idea of participation, which is defined by Frederick et al. as the level of involvement in academic activities, a crucial factor in achieving positive academic outcomes. Emotional engagement refers to positive and negative reactions to teachers, classmates, or the educational environment, which can influence the willingness to perform a task. Finally, cognitive engagement draws on the idea of investment, i.e., the mental effort spent to comprehend complex ideas and master difficult skills.

Studies have suggested that student engagement directly affects learning outcomes (Carini, et al., 2006). Other authors such as Klem and Connell (2004) refer to the advantages of having engaged students, as this increases academic performance and prompts students to persist and allocate attention to their learning. As Pascarella (2001) argued, successful educational settings are often part of institutions that are concerned with students' academic and social engagement. More recently, Kahu and Nelson (2018) provided a framework on the relationship between student engagement and student success, identifying three main factors affecting the relationship: the interaction between students and institutions; psychosocial constructs such as emotion, wellbeing, self-efficacy, and belonging; and the demographic characteristics of the students.

\section{Engagement in Fully Online Learning Environments (FOLEs)}

Engagement in FOLEs has been researched in several learning settings. Low retention rates of students in online courses (Perna et al., 2014) highlight the need to focus on ways in which to secure online attendance for lectures and offline interaction with materials. Although the use of online communication platforms such as Zoom has increased due to the COVID-19 pandemic (Dhawan, 2020), Malaysian learners seem to display negative views towards continuing their studies in FOLEs (Chung et al., 2020). In the United States and Canada, student engagement has been measured by means of the national survey of student engagement (NSSE). This survey provides benchmarks on various aspects of student engagement such as the level of academic challenge, active or collaborative learning, student-faculty interaction, educational experiences, and supportive campus environment. An online component was included in 2007 that acknowledged the prevalence of online learning environments (Chen et al. 2010; Meyer, 2014). Student engagement in online learning settings poses new issues for instructional designers, who require more empirical research to advance knowledge in this area (Czerkawski \& Lyman, 2016). With a focus on web-based learning technology, Chen et al., (2010) administered the NSSE to 17,819 respondents, and reported a positive relationship between the technologies employed in a course and levels of engagement in terms of interaction, collaborative group work, and reflective learning. Czerkawski and Lyman (2016) acknowledged the role of the instructor, the instructional designer, and instructional design in the literature and created an e-learning engagement framework focused on interaction, collaboration, facilitation, and feedback. This approach includes four phases - instructional needs, instructional objectives, learning environments, and summative assessment - that are meant to work as a procedural framework for instructors to add effective practices that increase student engagement. Focusing on the online collaborative discussion posts of 49 students enrolling in an online educational psychology course, Raković et al. (2020) identified attributes of the posts that prompted high levels of engagement in a Canvas online discussion forum. The authors found that specific rhetorical moves such as asking questions, requesting justification, and making a claim prompted the highest number of responses, which is in line with previous findings (Nandi et al., 2012), and highlights the role of instructors and learners in the promotion of constructive online discussion settings that result in learning achievement. Facilitating discourse is a feature of adequate 
teaching presence that can be increased by raising questions, making observations, steering the discussion, and engaging inactive learners (Garrison \& Arbaugh, 2007).

\section{Engagement and FOLEs in EFL Studies}

Regarding EFL studies exploring engagement in fully online learning environments (FOLEs), Yen et al. (2015) conducted research on enhancing students' writing and speaking skills using Facebook (asynchronous online discussions) and Skype (synchronous online discussions) as learning tools. The participants were 42 students from a business college in Taiwan who were enrolled in an EFL conversation course. They were asked to sit a proficiency test to assess writing and speaking levels, to engage in online conversational role-playing activities through Skype, and to participate in Facebook group discussions over a period of 11 weeks. The findings suggested that using computer-based technologies contributed to increasing the participants' EFL learning skills and that engagement increased as anxiety levels were reduced through such activities.

The varied nature of the components of engagement calls for the need to include several aspects of L2 engagement in online settings. Thus, Sun (2014) investigated the difficulties that 46 EFL learners faced when adapting to fully online learning environments. Sun identified four main aspects that could impact engagement in online L2 settings: participation, group work, learning strategies, and instructional materials. With respect to participation and group work, these are relevant to increasing online engagement, as CMC learning "does not automatically ensure the successfulness of the integration of CMC into language education" (Nguyen, 2011, p. 1414). Learners may feel disconnected from their peers and from the language learning setting, which can engender negative attitudes towards online learning (Nor et al., 2012). Regarding learning strategies, the literature has shown that online communication can prompt students to acquire new skills that support learning (Sun, 2011) and generate self-regulation strategies mediated by technology (McLoughlin \& Lee, 2010). These strategies can have an effect on online EFL learning and switch the focus of learners from a large class setting to a more personalized, self-regulated learning environment (Sun, 2011). Finally, instructional materials play an important role in the teaching and learning process as they can enhance the level of participation and the strategic approach to the online setting (Sun, 2014). Through a mixed-methods design, Sun (2014) identified six main difficulties that were related to: (1) programme and study schedule, (2) finding time to work with classmates, (3) organizing collaborative work, (4) maintaining engagement with the class, (5) nurturing self-motivation, and (6) socialising. These inter-related aspects were mainly informed by two major sets of difficulties: interaction and collaboration and learning strategies, which suggests that engagement is a construct that cannot be measured without looking into the factors that hinder or facilitate its presence.

\section{Methodology}

\section{Research Design}

The present study applied a mixed-methods design to explore the perceptions of adult EFL learners, which allowed the researchers to tackle those perceptions from a triangulated perspective. First, a Likert-scale questionnaire was used to gather 54 learners' perceptions of FOLEs and their engagement. Then, seven participants with relevant response profiles were interviewed to further explore their responses on the questionnaire. Based on the research question posited, the main objective of the study was to explore the perceptions that these learners hold in relation to the aspects identified by Sun (2014) as influencing engagement, such as online participation, group work, instructional materials, and learning styles.

\section{Participants and Context}

The 54 EFL university learners who participated in the present study were selected by means of purposeful sampling, as it was necessary to choose participants that were knowledgeable about or experienced with a phenomenon (Creswell \& Creswell, 2018). Thus, these participants were chosen because they were EFL learners taking part in an FOLE EFL course at the university level via Blackboard Collaborate for the first time. The participants were majoring in geology and civil engineering and were native speakers of Spanish attending an EFL course that has an objective of achieving a B2 level (CEFR framework). An Oxford Quick Placement Test (OQPT) was used to assess the participants' proficiency level, which showed a mean score of 24 (lower B2 CEFR level). The FOLE course was delivered in emergency remote teaching (ERT) circumstances in 2020, so students had to switch from face-to-face EFL lessons to the FOLE by means of Blackboard Collaborate. This platform is a 
learning management system (LMS) that is used for web-conferencing and allows instructors to create virtual classrooms to interact with their students in real time. Blackboard Collaborate has been implemented in educational settings to connect students and teachers in a simulated online classroom. Some of its features include screen sharing, virtual hand raising, on-screen chat, and document sharing. In order to use Blackboard Collaborate, both teacher and students need computer access and a stable internet connection. This online tool has been extensively used in online university courses, which have reported its positive impact on performance (Moonsamy \& Govender, 2018) and engagement (Wdowik, 2014). The use of this platform within the selected FOLE included synchronous and asynchronous online learning activities.

\section{Instruments and Materials}

\section{FOLE Questionnaire}

The quantitative part of the study was based on the Likert-scale section of the instrument designed by Sun (2014) to explore students' perceptions of online learning (Appendix 1). This questionnaire contains 19 fivepoint scale items that tap into aspects of participation, group work, instructional material, and learning styles in FOLEs, and range from Strongly disagree (1) to Strongly agree (5). Sun reports good internal consistency for the four components in the instrument (Participation, Group work, Learning styles, and Instructional materials). An example of an item in the Participation component is "There was not enough opportunity for peer interaction. I found it more difficult to participate and engage in an online class than a traditional classroom." To prevent L2 proficiency from interfering with the understanding of the statements, they were translated into the participants' L1 (Spanish).

\section{Semi-structured Interview}

Sun's (2014) qualitative section of the survey included 13 open-ended questions about aspects of FOLEs to be answered in written form. However, we surmised that a qualitative approach based on semi-structured interviews would produce richer accounts of learners' perceptions, as these types of questions provide a wider range of freedom for participants to report on their views (Dunn, 2005), which becomes crucial when they discuss aspects of engagement. The interview protocol was modelled considering the answers given by the students in the FOLE questionnaire and included follow-up questions that sought to deepen our understanding of the participants' perceptions and attitudes towards FOLEs.

\section{Procedures}

\section{Pilot Study of the FOLE Questionnaire}

Since data collection was carried out online for both instruments, a Google Forms link to the FOLE questionnaire was created, and Zoom was used to conduct the interviews. A pilot version of the FOLE questionnaire was completed by ten students not taking part in the study. The document included a section for feedback on the structure of the questions, the clarity, and the length of the instrument. The feedback obtained was used to modify the wording of certain statements for comprehension, and to set a completion time for the questionnaire (15 minutes). Overall, the pilot study participants found the FOLE questionnaire clear and easy to understand, and no major issues with it were reported.

\section{Data Collection and Analysis}

Before collecting data, consent was secured with an email outlining information about the study and the type of participation required. Then, we administered the FOLE questionnaire by means of a Google Forms link. Participants were given a week to return the completed questionnaires and were asked to provide an email address for potential participation in the semi-structured interviews. The second stage for data collection involved conducting the interviews with seven participants selected from the 54 participants who completed the FOLE questionnaire. The questions included in the interview protocol focused on exploring reasons and explanations for their previous responses (e.g., In your opinion, was it necessary to have group work and collaboration in the classroom? Why?). These interviews were conducted in the participants' L1 and lasted 3040 minutes. As for data analysis, the research question in the study was discussed with both quantitative (descriptive statistics) and qualitative (interview data) approaches. While the former seeks to find general tendencies in the data (Dornyei, 2007), the latter employs qualitative content analysis, which organises the meaning of qualitative data in a systematic way (Schreier, 2012). Once the interviews were transcribed, a 
codification process was carried out (Creswell \& Creswell, 2018), identifying relevant codes and broad themes emerging from the analysis that served to label and hierarchically categorise the data.

\section{Results and Discussion}

\section{Quantitative Results and Discussion}

\section{Descriptive Statistics}

Table 1 below presents data from the FOLE questionnaire on all the components assessed, based on the first section of Sun's (2014) instrument. Following Oxford and Burry-Stock (1995), mean scores of 1.0 - 2.4 were regarded as displaying a low level of agreement with the component; mean scores of $2.5-3.4$ portrayed a medium level of agreement; finally, mean scores of 3.5 - 5.0 illustrated a high level of agreement. As can be seen in the table, the total mean score of the survey $(M=3.51 ; S D=.44)$ suggests that these participants had an overall positive attitude towards the FOLE, and that the online participation component prevented the total score from being higher.

\section{Table 1}

Descriptive statistics for FOLE quantitative questionnaire data

\begin{tabular}{lccccc}
\hline & $\boldsymbol{N}$ & Minimum & Maximum & Mean & Std. Dev. \\
\hline Online participation & 54 & 1.00 & 5.00 & 2.61 & .93 \\
Collaborative group work & 54 & 2.00 & 5.00 & 3.79 & .72 \\
Instructional materials & 54 & 2.83 & 5.00 & 4.05 & .67 \\
Learning strategies and styles & 54 & 1.80 & 4.80 & 3.37 & .71 \\
\hline Total scores & $\mathbf{5 4}$ & $\mathbf{2 . 5 8}$ & $\mathbf{4 . 4 7}$ & $\mathbf{3 . 5 1}$ & $\mathbf{. 4 4}$ \\
\hline
\end{tabular}

\section{Online participation}

The results show that students regarded online participation as the most lacking out of the four components assessed $(M=2.61 ; S D=.93)$. The participants' answers suggest that their perceptions of online participation were not overtly positive in their classes. Figure 1 below illustrates this trend for an item in this component.

\section{Figure 1}

Frequency values for answers to Item 1 (Online participation)

There was not enough opportunity for peer interaction. I found it more difficult to participate and engage in an online class than a traditional classroom.

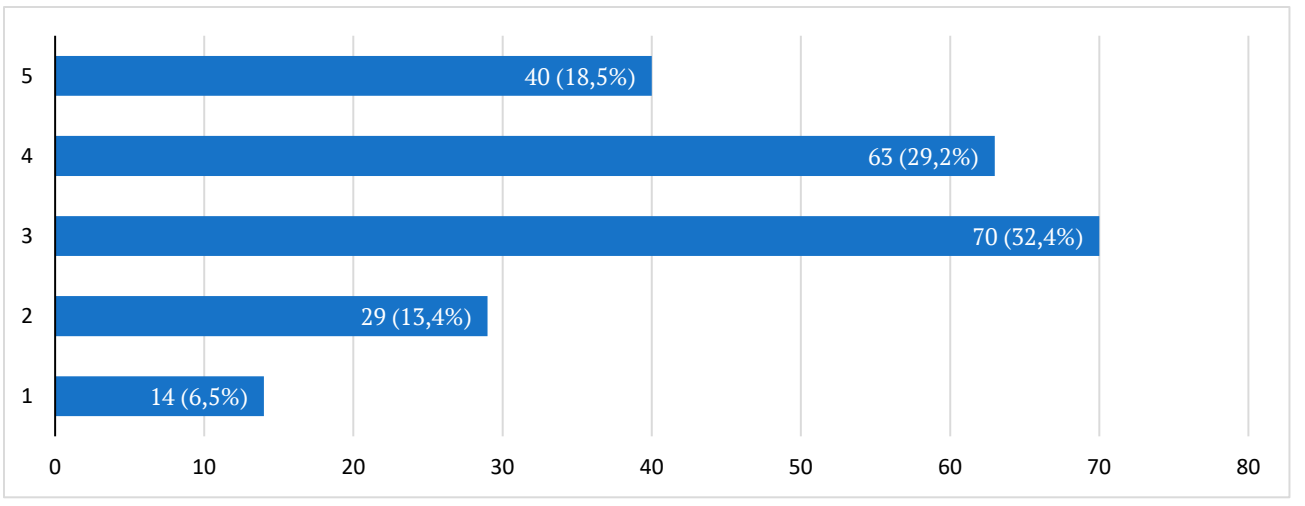

Note. Likert-scale ranges from Strongly disagree (1) to Strongly agree (5).

\section{Learning Strategies and Styles}

Regarding perceptions of learning strategies and styles in FOLE, students' responses $(M=3.37 ; S D=.71)$ displayed higher scores when compared to online participation but still implied learner neutrality towards self- 
directed and self-regulated processes that are relevant to FOLE. Figure 2 below depicts the response trend for learning styles.

\section{Figure 2}

Frequency values for answers to Item 18 (Learning strategies and styles)

My preferences, needs, social life, technology choices, etc. were better served by online learning.

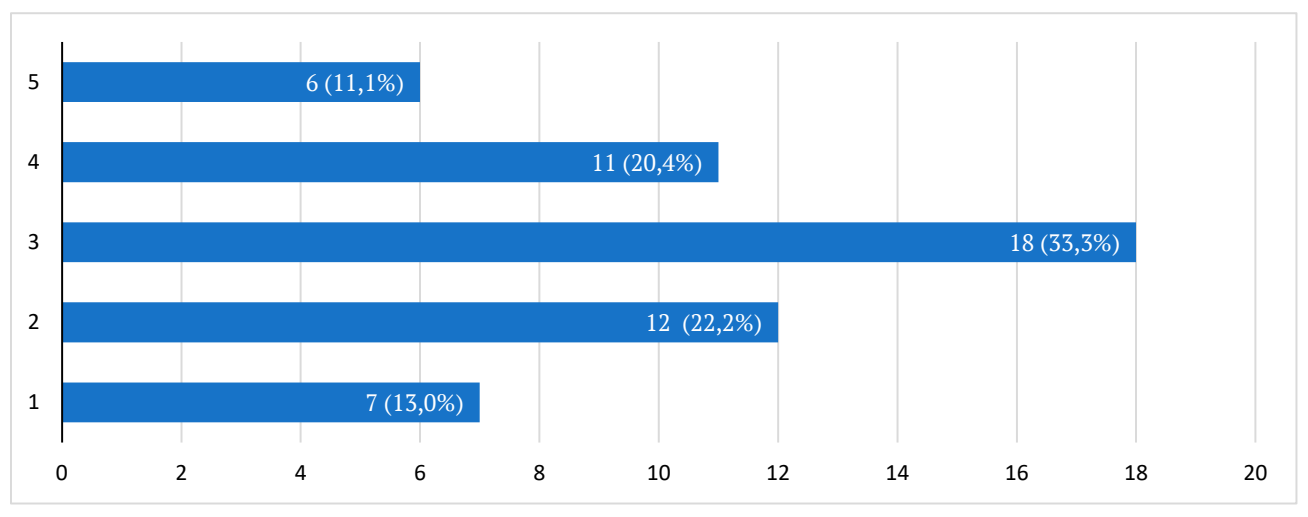

Note. Likert-scale ranges from Strongly disagree (1) to Strongly agree (5).

\section{Group Work}

Students regarded collaborative group work as a positive aspect of their online learning process $(M=3.79 ; S D=$ .72), over Online participation and Learning styles. Figure 3 below illustrates that responses for item 5 were mainly in agreement with group work activities. Interestingly, the positive attitudes towards group work did not reflect the views towards online participation.

\section{Figure 3}

Frequency values for answers to Item 5 (Collaborative group work)

I liked the group work we had to do in the online lessons.

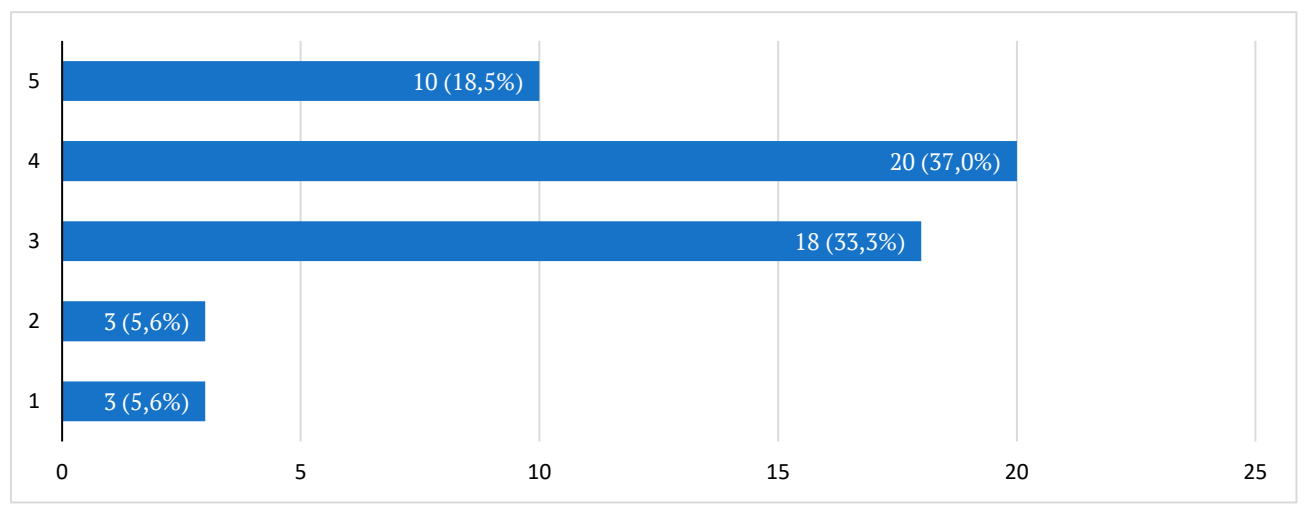

Note. Likert-scale ranges from Strongly disagree (1) to Strongly agree (5).

\section{Instructional Materials}

Finally, the data revealed that the most highly regarded component for these students was Instructional materials $(M=4.05 ; S D=.67)$. Figure 4 displays results for item 11 . 


\section{Figure 4}

Sample of frequency values for answers to Item 11 (Instructional materials)

Authentic learning materials should sometimes be used in the online lessons.

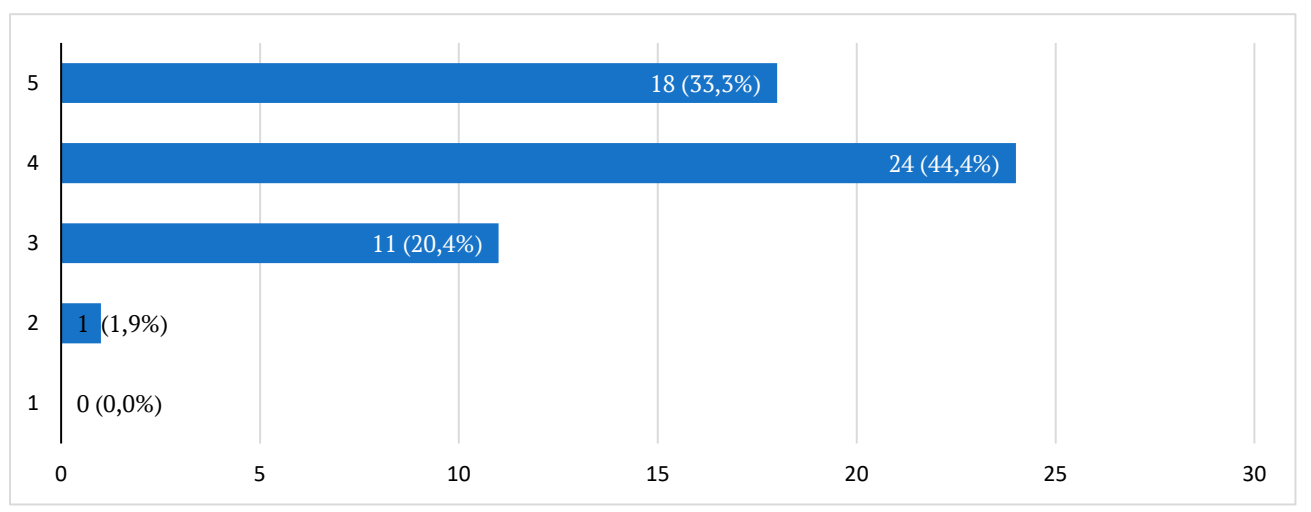

Note. Likert-scale ranges from Strongly disagree (1) to Strongly agree (5).

\section{Quantitative Discussion: What Are University EFL Learners' Perceptions of their Engagement Towards Aspects of their FOLE Lessons?}

The quantitative data showed that the main perceptions of learners are salient in terms of their attitudes towards online participation, which is evidenced by the low-moderate means displayed in the component. These attitudes are in line with Sampurna et al., (2018), who reported lower levels of participation from students in non-formal language teaching settings using online platforms such as Facebook and chat tools. The characteristics of the learning setting (a learning support course not attached to an educational institution) may have increased the lack of involvement found in that study. In line with this, Sun (2014) reported that students were only able to interact in small groups in online contexts. While her students stated that they did interact in online settings, their interaction was typically limited to collaboration with one partner, and that further instances for interaction were hindered by the lack of initial rapport with students they did not know. We wanted to explore the reasons behind our findings in terms of online participation, so we pursued this component further in the semi-structured interviews to address the adaptation issues faced by students in this new online learning environment. The fact that online participation is perceived as the weakest aspect by the participants in our study learners is concerning, as the quantity and quality of student participation in online courses is directly related to academic performance (Duncan et al., 2012). With respect to perceptions of learning strategies and styles in FOLEs, results showed higher scores when compared to online participation but still implied learner neutrality towards self-directed and self-regulated processes. Such processes are crucial to nurturing successful learning environments, as teacher guidance may not be enough on its own (Sun, 2014). The higher means reported for the group work component are similar to the positive perceptions reported by Zhu (2012), who found that students were satisfied with collaborative work and aware of its relevance in the learning process. Finally, the positive reactions towards content materials highlight the level of appreciation for engaging materials that are designed by teachers but consider learner feedback in their creation. Furthermore, if students are exposed to materials that are meaningful for them - i.e., materials that prompt self-regulation and collaboration - they will become more engaged with the course (Kebritchi et al., 2017). These two aspects (instructional materials and group work) represent the two highest means found in the present study, which shows how these learners' perceptions of the FOLE course are influenced by the quality of the content in the classes.

\section{Qualitative Findings and Discussion}

\section{Participants' Profiles}

As was stated before, seven participants were selected from the total sample $(n=54)$ of participants completing the FOLE questionnaire. The selection of the participants was based on their mean scores in specific components. For example, participant 1 was interviewed because his positive views on instructional materials 
(IM), and his rather low score on online participation (OP). These types of participants were regarded as relevant for interviewing because we wanted to explore their reasons behind their negative perceptions, and how they would interact across such components. We also included participants with medium levels of agreement towards a given component when a difference with other components was established in their profile (e.g., participant 3). Seven participants with distinct profiles were identified with this process and were asked to participate in the interviews. Table 2 below shows a general profile description of the participants.

\section{Table 2}

Interview participants' profiles

\begin{tabular}{|c|c|c|c|}
\hline Participants & Program & Gender & Profile \\
\hline Participant 1 & Civil engineering & Male & $\begin{array}{l}\text { High IM }(\mathrm{M}=4.83) \\
\text { Low OP }(\mathrm{M}=2.25)\end{array}$ \\
\hline Participant 2 & Civil engineering & Male & $\begin{array}{l}\text { High GW }(\mathrm{M}=4.75) \\
\text { Medium OP }(\mathrm{M}=2.50)\end{array}$ \\
\hline Participant 3 & Geology & Male & $\begin{array}{l}\text { Medium LS }(\mathrm{M}=3.40) \\
\text { Low OP/GW }(\mathrm{M}=2.25)\end{array}$ \\
\hline Participant 4 & Civil engineering & Male & $\begin{array}{l}\text { High GW }(\mathrm{M}=3.75) \\
\text { Low OP }(\mathrm{M}=2.25)\end{array}$ \\
\hline Participant 5 & Geology & Female & $\begin{array}{l}\text { High GW/IM }(\mathrm{M}=4.50) \\
\text { Low OP }(\mathrm{M}=1.00)\end{array}$ \\
\hline Participant 6 & Geology & Male & $\begin{array}{l}\text { Medium IM }(\mathrm{M}=3.33) \\
\text { Low LS }(\mathrm{M}=2.00)\end{array}$ \\
\hline Participant 7 & Geology & Male & $\begin{array}{l}\text { High GW }(\mathrm{M}=4.50) \\
\text { Medium OP }(\mathrm{M}=2.75)\end{array}$ \\
\hline
\end{tabular}

Note. $\mathrm{GW}=$ Group work IM = Instructional materials $\mathrm{OP}=$ Online participation LS = Learning styles

\section{Main Themes}

Analysis of the interviews yielded several themes that were associated with the four components in Sun's (2014) FOLE questionnaire. However, the first two components (namely, Online participation and Group work) were found to overlap strongly in the responses provided by participants, who attributed similar meanings to both. Therefore, the two components were merged into one. The analysis of the interviews provided below will refer to the themes impacting three main components: Online participation, Learning strategies and styles, and Instructional materials.

Online Participation: Interactions among Peers and Peer Rapport. The themes that emerged in this category are related to the interactions between students that can benefit or hinder learners' perceptions of FOLE classes, and the quality of the rapport with specific students. For example, participant 5 (High GW/IM, Low OP) manifested difficulties interacting with peers as a main reason for giving low ratings to the Online participation component:

I think (the class) is unsatisfactory because I compare it with face-to-face classes, and it is not the same. Interaction among coursemates is not the same because it is limited to chat and to have a group work by the end of the class that is just two or three people.

This learner seemed frustrated with FOLE lessons because it was difficult for her to establish meaningful communication with her peers. This lack of social interactions among students is a factor that impinges upon a successful educational experience (Muilenburg \& Berge, 2005). Student-student interactions can be a source for cognitive presence and a driver of motivation (Bernard et al., 2009) and can encourage critical thinking and prompt students to reflect on learning (Mills et al., 2016). This can be illustrated by participant 3's (Medium LS, Low OP/GW) dissatisfaction with the lack of peer interaction instances, as they prevented him from receiving peer feedback, which in turn may affect his motivation to learn: 
Another difference that I have noticed is that in (face-to-face) classes I can sometimes approach the classmate that is next to me and ask him/her: "Hey, what was that again?" and you could immediately understand. In an online modality, no, you can't do that.

In line with this, students referred to the quality of the interactions obtained when they do not know their peers taking part in the FOLE lesson:

Participant 2 (High GW, Medium OP): "For example, suddenly you had to do group work with new people that you didn't know, for example, people from other cities. These EFL lessons include students from all the campuses, and I even had colleagues from other programmes."

Participant 6 (Medium IM/Low LS): “You don't know anybody, and you don't know how the other person will react if you ask him/her something or if you say to him/her: 'Let's do this.”

These students reported their reluctancy to interact with unknown classmates from different departments in their EFL FOLE lessons because they felt that the lack of rapport with such students leads to poor collaborative work. Indeed, adequately sharing task objectives can help develop useful learning skills and a better understanding of the content (Brindley et al., 2009). The interaction issues identified are closely related to Sun's (2014) findings, which showed that students reported limited opportunities for socialisation and interaction. Opportunities for collaboration among peers are crucial in the design of effective online learning environments (Czerkawski \& Lyman, 2016). Moreover, encouraging students to increase online contact with each other is a predominant variable when predicting learning outcomes (Lundberg \& Sheridan, 2015), as it allows for the nurturing of a social presence in the online community that can in turn improve socio-emotional outcomes in the course (Garrison \& Arbaugh, 2007). It is challenging for students to develop the trust in their course mates that can lead to a sense of 'online camaraderie' (Garrison \& Arbaugh, 2007), but skilled instructors can facilitate these interactions by means of the FOLE platforms being used. It would seem that for these students, the lack of social presence is preventing them from achieving a more complete cognitive presence, as they would in face-to-face learning. The extracts underscore the importance of the affective function in establishing social presence and, perhaps more importantly, illustrate the opportunity for the instructor to increase teaching presence and create a non-threatening learning environment that help develops language skills (Murphy, 2015).

Learning Strategies: Adaptation to External Issues, Adaptation to Class Schedules, Self-regulated Strategies. With respect to learning strategies and styles, we identified three closely related themes: Adaptation to external issues, Adaptation to class schedules, and Self-regulated strategies. Participants perceived that awareness of their particular learning styles is relevant for learning and entails the nurturing of a self-regulated process that enhances academic achievement outcomes (Barnard-Brak et al., 2010). Regarding adaptation to external issues influencing the FOLE experience, participant 6 (Medium IM/Low LS) referred to them in relation to his performance in the class:

The most complex thing is to be able to pay attention in an EFL class because (my) internet connection is not that good, and few students have good internet.

What this participant expresses evidences the potential logistic issues that are involved in setting up an online environment. Further evidence of the existence of external issues is related to fatigue due to prolonged Blackboard sessions, as participant 7 (High GW, Medium OP) reports:

I think I need glasses that reduce eyestrain, and I do not wear glasses at all. I spend too much time in front of a screen, and most of the time I feel that my eyes are tired.

These types of external factors are regarded as secondary compared to factors directly related to the class experience (Liu et al., 2010). However, such factors may gain more relevance in EFL contexts that lack a set of guidelines to organise the way in which lessons are delivered. Participant 1 (High IM, Low OP) reported an adaptation issue in relation to his class schedule:

The classes are delivered back-to-back sometimes, and lunch breaks are very short. Sometimes I have lunch very late, and it is about mental fatigue, more than anything, spending all day in front of a screen.

Participant 1 seems to be affected by mental fatigue, which renders him unable to overcome the difficulties caused by the new organization of his online schedule. This is not uncommon in students, as Chen et al. (2008) 
found that some participants did not hold positive views on the temporal and spatial flexibility that online courses can provide. Another extract focusing on the scheduled time of the classes was provided by participant 4 (High GW, Low OP):

It is difficult to adapt to the schedules because going to face-to-face classes is different from attending classes through a computer. Over time, it becomes easier. You get used to it.

The comment made by participant 4 reveals that the adaptation process may improve once the participant becomes more familiar with the new learning environment. This is in agreement with a case study investigation conducted by Ayebi-Arthur (2017), who concluded that students eventually become more resilient after engaging and re-engaging with online learning. It can be argued that increased awareness towards effective learning strategies can help learners navigate the adaptation process:

Participant 3 (Medium LS, Low OP/GW): “The class was all self-taught, so in the end I focused on my own actions to study, but I was always guided by what (the teacher) told me in class; otherwise, it wouldn't have made sense."

Participant 5 (High GW/IM, Low OP): "Well, I think that a good part of online learning is that we have the lessons recorded, so if there is something that I did not understand, I can go and listen to it over and over. Or if they upload material (to the platform), I can go and check it while I watch the class [...] In face-to-face classes, if you could not attend classes you would just lose the content of the class, and you would keep your questions to yourself."

These students stated a preference for a self-regulated learning process where they expect and accept the guidance from the teacher, who is seen as the expert who can create constructive online learning settings (Nandi et al., 2012), but can also implement activities that increase self-directed learning (Lambert \& Fisher, 2013). Although online learning environments represent challenging activities for learners who are adapting to them (Kebritchi et al., 2017; Luyt, 2013), learners can benefit from teacher guidance together with a selfregulated approach to the online classroom. Increased awareness of the relevance of the FOLE for language learning is strongly connected to self-regulation processes (Baran et al., 2011; Kebritchi et al., 2017), and student-instructor interaction can create and nurture such processes, while at the same time providing emotional and motivational support (Bernard et al., 2009). In addition, adequate teacher guidance can also increase students' levels of awareness and satisfaction with the course (Lee et al., 2011).

Instructional Materials: Class Planning, Content, Online Platform Instruction. Since perceptions towards instructional materials was the highest rated component on the FOLE questionnaire, participants reported mainly positive perceptions towards it, focusing on three main themes: Class planning, Content, and Online platform instruction. Participant 7 (High GW, Medium OP) pointed out a good FOLE experience by means of class planning:

I find that the method used by the teacher is very good because she gives us examples. I mean, she talks about some examples and then she gives us some activities. Then, she tells us that anyone can write on the interactive board.

This participant feels that the class planning performed by the teacher fulfils his expected learning objectives. This was a common theme among the participants, as most of them reported that a well-planned class fostered their motivation towards online learning. The appropriate introduction of self-learning skills by the teacher as described by participant 7 allows teachers to help learners develop self-regulated strategies in online courses (Baran et al., 2011). The disposition of the instructor towards increasing participation in students is essential for helping students feel they are part of an online classroom experience (Comas-Quinn, 2011). Satisfaction with the content of the class organised by the teacher was also reported by participants 4 and 5 , who expressed satisfaction with the content of the class:

Participant 4 (High GW, Low OP): “The teacher is always trying to search for material that talks about what we study since I share my English course with geology and metallurgical engineering."

Participant 5 (High GW/IM, Low OP): "I like the material that this teacher gives and how she conducts the classes that focus mainly on geology topics, which is what we study. She is constantly asking what deficiencies we have, or what is right or what is wrong (in the class), so as a class group we tell her about the material (that they would like to see in the class) and she finds it for us." 
These extracts represent the general perception that students have about the materials used in the FOLE lessons, which rely heavily on the quality of the content and its meaningfulness. Content that is relatable to some aspect of learners' lives and considers their needs during online courses can be more relevant and thus prompt further engagement (Chametzky, 2014; Mills et al., 2016). The students also recognised the teacher's efforts to include feedback in her online classes, which increases engagement with class planning, and nurtures the cognitive presence of the students as they go from an information-seeking state to a resolution stage in a community of inquiry. Participant 5 also refers to the immediacy of the feedback, which is a crucial feature in online environments (Mills et al., 2016) and a reflection of the expertise of the instructor regarding both the content and the pedagogy (Garrison \& Arbaugh, 2007).

Some participants held negative perceptions towards the instructions provided to use the online platform. Participants 3 and 6 displayed negative views towards the instruction process before accessing the online platform:

Participant 3 (Medium LS, Low OP): “I think that there was a lack of delivered instructions about Blackboard because we were still learning how to use it as we started the course. Suddenly, there were notifications on my screen, and I had no idea how to access them."

Participant 6 (Medium IM/Low LS): "They (the university) told us that we have to get on the Blackboard platform and there are all your courses, and you will have your classes (there). So, at the beginning (I was) like: "Where do I get in the class?", or: "Where do I raise my hand?", and: "How do I turn on my microphone?"

The issues presented in these extracts suggest that teachers need to take into account their learners' levels of awareness of Blackboard and other technologies, along with their ability to understand and use them (Hussein, 2016). Instructional materials will be effective only if learners' awareness of how to access them and take advantage of them is improved. Students demand online environments that allow them to be in control by means of flexible technological tools (Tabor, 2007). To achieve this, the interactions between the students and the content must include accurate and complete information in relation to the learning activities, the assignments required, and any supporting materials (Siragusa et. al., 2007). In addition, some level of technical competence is required from students so that they can apply creativity and achieve a 'sense of puzzlement', that is, a desire for further inquiry and information exchange (Murphy, 2015). This relevance of the delivery aspect of instructional materials and its matching with the online learning skills of students has also been underscored by Delen et al. (2014), who argued that including supplemental functions for instructions in online environments with specific user needs in mind will enhance learning. Providing personal insights regarding the structure of the course and guidelines to use the medium more effectively are desirable activities for instructors to help tackle learnercontent interaction issues (Caskurlu et al., 2021; Garrison \& Arbaugh, 2007).

Overall, the qualitative aspect of the research question posed in the present study provided more specific insights into these learners' perceptions and attitudes towards FOLEs. Aspects of online participation and group work, learning strategies, and instructional materials were found to influence the participants' experiences when taking part in a FOLE EFL course. Figure 5 below presents a summary of the exploratory findings reported in the qualitative section and how they influenced these learners' perceptions towards engagement with the course.

\section{Figure 5}

Aspects influencing FOLE perceptions of engagement

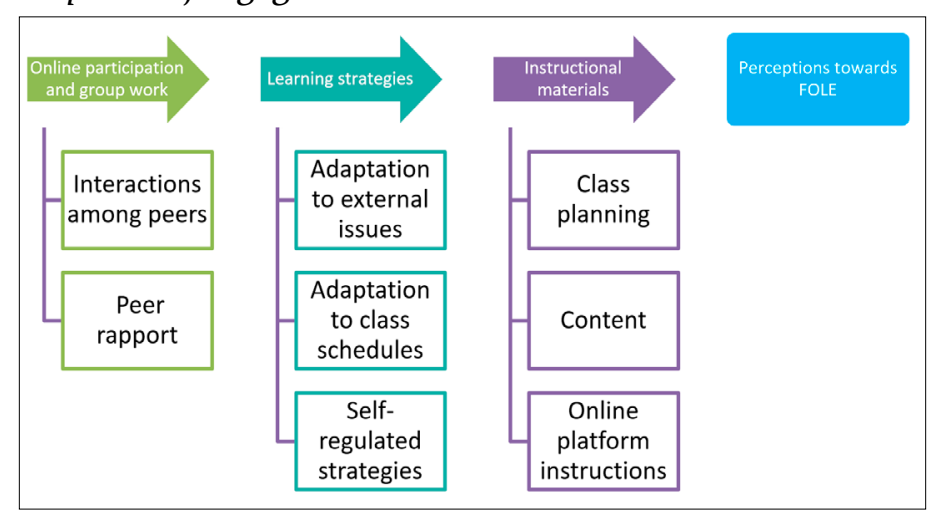




\section{Conclusion}

The present exploratory case study sought to understand the perceptions and difficulties faced by Chilean EFL university students when facing a fully online learning environment. The main findings revealed that students were not satisfied with the online EFL course in terms of the participation levels they expected. Semi-structured interviews evidenced that the poor interactions with peers and lack of peer rapport negatively influenced their social presence. Reported perceptions towards external issues, the class schedule, and self-regulated strategies used by learners suggest that the adaptation process can impinge upon the online classroom experience, and that the instructor can use teaching presence to motivate learners to become more aware of the relevance of the online environment and overcome those adaptation issues. Finally, the use of instructional materials was the highest rated component in the FOLE questionnaire. The interviews revealed that students focused on three main aspects to discuss the materials: Class planning, Content, and Online platform instruction. These aspects highlight the importance of the delivery of the instructions to achieve task goals in FOLEs, and the value of increasing teaching presence to help develop cognitive presence in these learners.

It must be noted that this study is exploratory in nature, and it focused on a specific learning context (namely, Chilean adult EFL learners who were required to attend FOLE classes in 2020). The unexpected nature of the changes to the modality of the classes delivered prevented the researchers from reaching a larger number of participants for both the quantitative and qualitative parts of the study. Furthermore, the participants were exposed to one semester of FOLE classes before data collection, which may not represent an exhaustive account of more well-formed perceptions towards FOLEs. The inclusion of more participants with specific profiles for the interviews could have provided more data to confirm the findings presented here. Future studies will need to consider a larger sample in diverse learning settings to establish comparisons across learning contexts.

\section{Implications for Pedagogy}

In educational environments that have been influenced by COVID-19 restrictions, the way in which lessons were being delivered changed in 2020 . Online platforms have forced teachers and learners to adapt to the new circumstances. This study provided an overview of some of the aspects that were affected by these new circumstances, which can prompt teachers to consider learners' opinions when creating and delivering FOLE EFL lessons and materials. The relevance of effective instructional materials highlights the need for meaningful materials that are clearly explained under the guidance of the FOLE teacher. In addition, the results obtained in this study evidenced a need for training prior to the use of online platforms for academic purposes. This information is important for teachers when engaging in online lessons since instruction addressing the correct use of the platform is essential for them to know what to expect as they teach, and for learners to have a clear understanding of what is expected of them. The need to include teacher training that focuses on technical skills and online pedagogical adaptations in institutions that offer courses based on distance education (Hampel \& Stickler, 2005) gains even more relevance in the online learning settings researched in the present study. Being aware of the perceptions towards the issues reported by FOLE students can only improve the approach to EFL in online learning settings and can allow teachers to focus on acquiring new tools and strategies that can foster online learner engagement.

\section{Declaration of Competing Interest}

None declared

\section{References}

Allen, I. E., \& Seaman, J. (2013). Changing course: Ten years of tracking online education in the United States. Babson Survey Research Group and Quahog Research Group. http://www.onlinelearningsurvey.com/reports/ changingcourse.pdf

Anderson, T., Rourke, L., Garrison, D. R., \& Archer, W. (2001). Assessing teaching presence in a computer conferencing context. Journal of Asynchronous Learning Networks, 5(2), 1-17. https://doi.org/10.24059/olj. v5i2.1875 
Arbaugh, J. B., \& Benbunan-Finch, R. (2006). An investigation of epistemological and social dimensions of teaching in online learning environments. Academy of Management Learning \& Education, 5(4), 435-447. https://doi.org/10.5465/amle.2006.23473204

Axelson, R. D., \& Flick, A. (2010). Defining student engagement. Change: The Magazine of Higher Learning, 43(1), 38-43. https://doi.org/10.1080/00091383.2011.533096

Ayebi-Arthur, Kofi (2017). E-learning, resilience and change in higher education: Helping a university cope after a natural disaster. E-Learning and Digital Media, 14(5), 259-274. https://doi.org/10.1177/2042753017751712

Bailey, D. R., \& Lee, A. R. (2020). Learning from experience in the midst of covid-19: Benefits, challenges, and strategies in online teaching. Computer-Assisted Language Learning Electronic Journal, 21(2), 178-198.

Bañados, E. (2013). A blended-learning pedagogical model for teaching and learning EFL successfully through an online interactive multimedia environment. CALICO Journal, 23(3), 533-550. https://doi.org/10.1558/ cj.v23i3.533-550

Baran, E., Correia, A.-P., \& Thompson, A. (2011). Transforming online teaching practice: Critical analysis of the literature on the roles and competencies of online teachers. Distance Education, 32(3), 421-439. https://doi. org/10.1080/01587919.2011.610293

Barnard-Brak, L., Paton, V. O., \& Lan, W. Y. (2010). Profiles in self-regulated learning in the online learning environment. International Review of Research in Open and Distributed Learning, 11(1), 61-80. https://doi. org/10.19173/irrodl.v11i1.769

Bernard, R. M., Abrami, P. C., Borokhovski, E., Wade, C. A., Tamim, R. M., Surkes, M. A., \& Bethel, E. C. (2009). A meta-analysis of three types of interaction treatments in distance education. Review of Educational Research, 79(3), 1243-1289. https://doi.org/10.1080/08923648909526659

Beatty, K. (2013). Teaching \& researching: Computer-assisted language learning. Routledge. https://doi. org/10.4324/9781315833774

Brindley, J., Blaschke, L. M., \& Walti, C. (2009). Creating effective collaborative learning groups in an online environment. The International Review of Research in Open and Distributed Learning, 10(3), 1-18. https://doi. org/10.19173/irrodl.v10i3.675

Cancino, M. \& Díaz, G. (2020). Exploring the code-switching behaviours of Chilean EFL high school teachers: A function-focused approach. Profile: Issues in Teachers'Professional Development, 22(2), 115-130. https://doi. org/10.15446/profile.v22n2.81152

Carini, R. M., Kuh, G. D., \& Klein, S. P. (2006). Student engagement and student learning: Testing the linkages. Research in Higher Education, 47(1), 1-32. https://doi.org/10.1007/s11162-005-8150-9

Caskurlu, S., Richardson, J. C., Maeda, Y., \& Kozan, K. (2021). The qualitative evidence behind the factors impacting online learning experiences as informed by the community of inquiry framework: A thematic synthesis. Computers \& Education, 165, 404111. https://doi.org/10.1016/j.compedu.2020.104111

Cavus, N. (2013). Selecting a learning management system (LMS) in developing countries: Instructors' evaluation. Interactive Learning Environments, 21(5), 419-437. https://doi.org/10.1080/10494820.2011.584321

Chametzky, B. (2014). Andragogy and engagement in online learning: Tenets and solutions. Creative Education, 5(10), 813-821. https://doi.org/10.4236/ce.2014.510095

Chen, P. S. D., Lambert, A. D., \& Guidry, K. R. (2010). Engaging online learners: The impact of Web-based learning technology on college student engagement. Computers \& Education, 54(4), 1222-1232. https://doi. org/10.1016/j.compedu.2009.11.008

Chen, R. T. H., Bennett, S., \& Maton, K. (2008). The adaptation of Chinese international students to online flexible learning: Two case studies. Distance Education, 29(3), 307-323. https://doi.org/10.1080/01587910802395821

Chung, E., Subramaniam, G., \& Christ Dass, L. (2020). Online Learning Readiness Among University Students in Malaysia Amidst Covid-19. Asian Journal of University Education, 16(2), 46-58. https://doi.org/10.24191/ ajue.v16i2.10294

Coates, H. (2007). A model of online and general campus-based student engagement. Assessment \& Evaluation in Higher Education, 32(2), 121-141. https://doi.org/10.1080/02602930600801878

Comas-Quinn, A. (2011). Learning to teach online or learning to become an online teacher: an exploration of teachers' experiences in a blended learning course. ReCALL, 23(3), 218-232. https://doi.org/10.1017/ s0958344011000152

Creswell, J. W., \& Creswell, J. D. (2018). Research design: Qualitative, quantitative, and mixed methods approaches (5th ed.). SAGE.

Crystal, D. (2006). English worldwide. In R. Hogg, \& D. Denison (Eds.), A history of the English language (pp. 420439). Cambridge University Press.

Czerkawski, B. C., \& Lyman, E. W. (2016). An instructional design framework for fostering student engagement 
in online learning environments. TechTrends, 60(6), 532-539. https://doi.org/10.1007/s11528-016-0110-z

Dahlstrom-Hakki, I., Alstad, Z., \& Banerjee, M. (2020). Comparing synchronous and asynchronous online discussions for students with disabilities: The impact of social presence. Computers \& Education, 150, 103842. https://doi.org/10.1016/j.compedu.2020.103842

Delen, E., Liew, J., \& Willson, V. (2014). Effects of interactivity and instructional scaffolding on learning: Self-regulation in online video-based environments. Computers \& Education, 78, 312-320. https://doi. org/10.1016/j.compedu.2014.06.018

Dhawan, S. (2020). Online Learning: A Panacea in the Time of COVID-19 Crisis. Journal of Educational Technology Systems, 49(1), 5-22. https://doi.org/10.1177/0047239520934018

Dörnyei, Z. (2007). Research methods in Applied Linguistics. Oxford University press.

Duncan, K., Kenworthy, A., \& McNamara, R. (2012). The effect of synchronous and asynchronous participation on students' performance in online accounting courses. Accounting Education, 21(4), 431-449. https://doi.or $\mathrm{g} / 10.1080 / 09639284.2012 .673387$

Dunn, K. (2005) 'Interviewing'. In I. Hay (Ed.), Qualitative research methods in human geography (pp. 79-105). Oxford University Press.

Fredricks, J. A., Blumenfeld, P. C., \& Paris, A. H. (2004). School engagement: Potential of the concept, state of the evidence. Review of Educational Research, 74(1), 59-109. https://doi.org/10.3102/00346543074001059

Garrison, D. R., \& Arbaugh, J. B. (2007). Researching the community of inquiry framework: Review, issues, and future directions. The Internet and Higher Education, 10(3), 157-172. https://doi.org/10.1016/j. iheduc.2007.04.001

Garrison, D. R., Anderson, T., \& Archer, W. (2000). Critical inquiry in a text-based environment: Computer conferencing in higher education. The Internet and Higher Education, 2(2-3), 87-105. https://doi.org/10.1016/ s1096-7516(00)00016-6

Garrison, D. R., Cleveland-Innes, M., \& Fung, T. S. (2010). Exploring causal relationships among teaching, cognitive and social presence: Student perceptions of the community of inquiry framework. The Internet and Higher Education, 13(1-2), 31-36. https://doi.org/10.1016/j.iheduc.2009.10.002

Hampel, R., \& de los Arcos, B. (2013). Interacting at a distance: A critical review of the role of ICT in developing the learner-context interface in a university language programme. Innovation in Language Learning and Teaching, 7(2), 158-178. https://doi.org/10.1080/17501229.2013.776051

Hampel, R., \& Stickler, U. (2005). New skills for new classrooms: Training tutors to teach languages online. Computer assisted language learning, 18(4), 311-326. https://doi.org/10.1080/09588220500335455

Herring, S. C. (1996). Computer-mediated communication: Linguistic, social and cross-cultural perspectives. Pragmatics and beyond series. John Benjamins.

Hodges, C., Moore, S., Lockee, B., Trust, T., \& Bond, A. (2020). The difference between emergency remote teaching and online learning. Educause review, 27, 1-12.

Hussein, H. E. G. M. (2016). The effect of blackboard collaborate-based instruction on pre-service teachers' achievement in the EFL teaching methods course at faculties of education for girls. English Language Teaching, 9(3), 49-67. https://doi.org/10.5539/elt.v9n3p49.

Hwang, A., \& Arbaugh, J. B. (2006). Virtual and traditional feedback-seeking Behaviors: Underlying competitive attitudes and consequent grade performance. Decision Sciences Journal of Innovative Education, 4(1), 1-28. https://doi.org/10.1111/j.1540-4609.2006.00099.x

Kahu, E. R., \& Nelson, K. (2018). Student engagement in the educational interface: Understanding the mechanisms of student success. Higher Education Research \& Development, 37(1), 58-71. https://doi.org/10. 1080/07294360.2017.1344197

Kebritchi, M., Lipschuetz, A., \& Santiague, L. (2017). Issues and challenges for teaching successful online courses in higher education. Journal of Educational Technology Systems, 46(1), 4-29. https://doi. org/10.1177/0047239516661713

Klem, A. M., \& Connell, J. P. (2004). Relationships matter: Linking teacher support to student engagement and achievement. Journal of School Health, 74(7), 262-273. https://doi.org/10.1111/j.1746-1561.2004.tb08283.x

Lambert, J. L., \& Fisher, J. L. (2013). Community of inquiry framework: Establishing community in an online course. Journal of Interactive Online Learning, 12(1), 1-16.

Lee, S. J., Srinivasan, S., Trail, T., Lewis, D., \& Lopez, S. (2011). Examining the relationship among student perception of support, course satisfaction, and learning outcomes in online learning. The Internet and Higher Education, 14(3), 158-163. https://doi.org/10.1016/j.iheduc.2011.04.001

Liu, I. F., Chen, M. C., Sun, Y. S., Wible, D., \& Kuo, C. H. (2010). Extending the TAM model to explore the factors that affect intention to use an online learning community. Computers \& education, 54(2), 600-610. https:// 


\section{SWITCHING TO FULLY ONLINE EFL LEARNING ENVIRONMENTS}

doi.org/10.1016/j.compedu.2009.09.009

Lundberg, C. A., \& Sheridan, D. (2015). Benefits of engagement with peers, faculty, and diversity for online learners. College Teaching, 63(1), 8-15. https://doi.org/10.1080/87567555.2014.972317

Luyt, I. (2013). Bridging Spaces: Cross-cultural perspectives on promoting positive online learning experiences. Journal of Educational Technology Systems, 42(1), 3-20. https://doi.org/10.2190/et.42.1.b

Marzban, A. (2011). Improvement of reading comprehension through computer-assisted language learning in Iranian intermediate EFL students. Procedia Computer Science, 3, 3-10. https://doi.org/10.1016/j. procs.2010.12.003

McLoughlin, C., \& Lee, M. J. W. (2010). Personalised and self-regulated learning in the Web 2.0 era: International exemplars of innovative pedagogy using social software. Australasian Journal of Educational Technology, 26(1), 28-43. https://doi.org/10.14742/ajet.1100

Mei, B., Brown, G. T., \& Teo, T. (2018). Toward an understanding of preservice English as a Foreign Language teachers' acceptance of computer-assisted language learning 2.0 in the People's Republic of China. Journal of Educational Computing Research, 56(1), 74-104. https://doi.org/10.1177/0735633117700144

Meyer, K. A. (2014). Student engagement online: What works and why. John Wiley \& Sons.

Mills, J., Yates, K., Harrison, H., Woods, C., Chamberlain-Salaun, J., Trueman, S., \& Hitchins, M. (2016). Using a community of inquiry framework to teach a nursing and midwifery research subject: An evaluative study. Nurse Education Today, 43, 34-39. https://doi.org/10.1016/j.nedt.2016.04.016

Moonsamy, D., \& Govender, I. (2018). Use of blackboard learning management system: An empirical study of staff behavior at a South African University. EURASIA Journal of Mathematics, Science and Technology Education, 14(7), 3069-3082. https://doi.org/10.29333/ejmste/91623

Muilenburg, L. Y., \& Berge, Z. L. (2005). Student barriers to online learning: A factor analytic study. Distance Education, 26(1), 29-48. https://doi.org/10.1080/01587910500081269

Murphy, L. (2015). Online language teaching: The learner's perspective. In R. Hampel (Ed.), Developing online language teaching (pp. 45-62). Palgrave Macmillan.

Nandi, D., Hamilton, M., \& Harland, J. (2012). Evaluating the quality of interaction in asynchronous discussion forums in fully online courses. Distance education, 33(1), 5-30. https://doi.org/10.1080/01587919.2012.667957

Nguyen, L. V. (2011). Learners' reflections on and perceptions of computer mediated communication in a language classroom: A Vietnamese perspective. Australasian Journal of Educational Technology, 27(8), 14131436. https://doi.org/10.14742/ajet.901

Nickerson, C. (2010). The Englishes of business. In A. Kirkpatrick (Ed.), The Routledge Handbook of World Englishes (pp. 509-519). Routledge.

Nor, N. F. M., Hamat, A., \& Embi, M. A. (2012). Patterns of discourse in online interaction: Seeking evidence of the collaborative learning process. Computer Assisted Language Learning, 25(3), 237-256. https://doi.org/10.1 080/09588221.2012.655748

Oxford, R. L., \& Burry-Stock, J. A. (1995). Assessing the use of language learning strategies worldwide with the ESL/EFL version of the Strategy Inventory for Language Learning (SILL). System, 23(1), 1-23. https://doi. org/10.1016/0346-251x(94)00047-a

Pascarella, E. T. (2001). Identifying excellence in undergraduate education are we even close? Change: The Magazine of Higher Learning, 33(3), 18-23. https://doi.org/10.1080/00091380109601796

Pellas, N. (2014). The influence of computer self-efficacy, metacognitive self-regulation and self-esteem on student engagement in online learning programs: Evidence from the virtual world of second life. Computers in Human Behavior, 35, 157-170. https://doi.org/10.1016/j.chb.2014.02.048

Perna, L. W., Ruby, A., Boruch, R. F., Wang, N., Scull, J., Ahmad, S., \& Evans, C. (2014). Moving through MOOCs: Understanding the progression of users in massive open online courses. Educational Researcher, 43(9), 421432.

Postmes, T., \& Spears, R. (1998). Deindividuation and antinormative behavior: A meta-analysis. Psychological Bulletin, 123(3), 238-259. https://doi.org/10.1037/0033-2909.123.3.238

Raković, M., Marzouk, Z., Liaqat, A., Winne, P. H., \& Nesbit, J. C. (2020). Fine grained analysis of students' online discussion posts. Computers \& Education, 157, 103982 https://doi.org/10.1016/j.compedu.2020.103982

Raza, S. A., Qazi, W., Khan, K. A., \& Salam, J. (2021). Social isolation and acceptance of the Learning Management System (LMS) in the time of COVID-19 pandemic: An expansion of the UTAUT model. Journal of Educational Computing Research, 59(2), 183-208 https://doi.org/10.1177/0735633120960421

Şahin Kızıl, A. (2020). Predicting achievement in distance language learning: A structural equation model. Open Learning: The Journal of Open, Distance and e-Learning, 1-17. https://doi.org/10.1080/02680513.2020.1787819

Sampurna, J., Kukulska-Hulme, A., \& Stickler, U. (2018). Exploring learners' and teacher's participation in online 
non-formal project-based language learning. International Journal of Computer-Assisted Language Learning and Teaching, 8(3), 73-90. https://doi.org/10.4018/ijcallt.2018070104

Schreier, M. (2012). Qualitative content analysis in practice. Sage publications.

Schultz, R. B., \& DeMers, M. N. (2020). Transitioning from emergency remote learning to deep online learning experiences in geography education. Journal of Geography, 119(5), 142-146. https://doi.org/10.1080/002213 41.2020 .1813791

Seaman, J. E., Allen, I. E., \& Seaman, J. (2018). Grade increase: Tracking distance education in the United States. Babson Survey Research Group.

Simonson, M., Zvacek, S. M. , \& Smaldino, S. (2019). Teaching and learning at a distance: Foundations of distance education (7th ed.). IAP Publishing.

Siragusa, L., Dixon, K. C. \& Dixon, R. (2007). Designing quality e-learning environments in higher education. In Proceedings of ASCILITE - Australian Society for Computers in Learning in Tertiary Education Annual Conference (pp. 923-935). Australasian Society for Computers in Learning in Tertiary Education.

Sun, S. Y.H. (2011). Online language teaching: The pedagogical challenges. Knowledge Management \& E-Learning: An International Journal, 3(3), 428-447. https://doi.org/10.34105/j.kmel.2011.03.030

Sun, S. Y. (2014). Learner perspectives on fully online language learning. Distance education, 35(1), 18-42. https://doi.org/10.1080/01587919.2014.891428

Tabor, S. W. (2007). Narrowing the distance. Implementing a hybrid learning model for information security management. The Quarterly Review of Distance Education, 8(1), 47-57.

Thurlow, C., Lengel, L., \& Tomic, A. (2004). Computer mediated communication. Sage.

Wang, Y., \& Chen, N. S. (2009). Criteria for evaluating synchronous learning management systems: arguments from the distance language classroom. Computer Assisted Language Learning, 22(1), 1-18. https://doi. org/10.1080/09588220802613773

Wang, G., Zhang, Y., Zhao, J., Zhang, J., \& Jiang, F. (2020). Mitigate the effects of home confinement on children during the COVID-19 outbreak. The Lancet, 395(10228), 945-947. https://doi.org/10.1016/S01406736(20)30547-X

Watson, W., \& Watson, S. L. (2007). An argument for clarity: What are learning management systems, What are they not, and What should they become? (2007). TechTrends, 51(2), 28-34. https://doi.org/10.1007/s11528007-0023-y

Wdowik, S. (2014). Using a synchronous online learning environment to promote and enhance transactional engagement beyond the classroom. Campus-Wide Information Systems, 31(4), 264-275. https://doi. org/10.1108/cwis-10-2013-0057

Yao, M. Z., \& Ling, R. (2020). "What Is computer-mediated communication? Journal of Computer-Mediated Communication, 25(1), 4-8. https://doi.org/10.1093/jcmc/zmz027

Yen, Y. C., Hou, H. T., \& Chang, K. E. (2015). Applying role-playing strategy to enhance learners' writing and speaking skills in EFL courses using Facebook and Skype as learning tools: A case study in Taiwan. Computer Assisted Language Learning, 28(5), 383-406. https://doi.org/10.1080/09588221.2013.839568

Zhu, C. (2012). Student satisfaction, performance, and knowledge construction in online collaborative learning. Journal of Educational Technology \& Society, 15(1), 127-136. 


\title{
APPENDIX
}

Adapted AND TRANSLATED statements based on Sun's (2014) FOLEs questionnaire

\author{
Participación (Preguntas 1-4) \\ Participation (Questions 1-4)
}

(1) No hubo suficientes oportunidades para la interacción entre pares. Me resultó más difícil participar en una clase en línea que en un aula tradicional. (There was not enough opportunity for peer interaction. I found it more difficult to participate and engage in an online class than a traditional classroom).

(2) En lugar de interactuar con muchas personas en una clase (interacciones multidimensionales), mis interacciones con mis compañeros a menudo se limitaban a un pequeño grupo de estudiantes de la clase. (Instead of interacting with many people in a class (multidimensional interactions), my interactions with classmates were often limited to a small group of classmates).

(3) Aprendí en un grupo pequeño en lugar de en una clase grande. Por ejemplo, solo practiqué con un grupo de compañeros de clase, ya que solo conocía un pequeño porcentaje de compañeros de lo que lo hubiera hecho en el aula tradicional. (I learnt in a small group rather than in a big class, e.g., I only practiced with a handful of classmates as I knew fewer classmates than I would have done in the traditional classroom setting).

(4) El Profesor necesitaba mucho trabajo para fomentar la construcción de una comunidad de aprendizaje en línea. (Much work was needed by the teacher to foster the building of an online learning community).

Trabajo en grupo. (preguntas de la 5-8)

Group work (Questions 5-8)

(5) Me gustó el trabajo grupal que tuvimos que hacer en las clases en línea. (I liked the group work we had to do).

(6) El trabajo grupal y el tipo de proyecto son partes importantes en el aprendizaje en línea. (Group work and project-type work are important parts in online learning).

(7) Se debe fomentar la cooperación y colaboración de los alumnos en el aprendizaje en línea. (Learner cooperation and collaboration should be encouraged in online learning).

(8) Debía haber más discusiones grupales sobre asuntos relacionados con el estudio entre los estudiantes y los profesores. (There needed to be more group discussions on study-related matters amongst class members and with the teachers.)

Material instructivo. (Preguntas de la 9-14)

Instructional material (Questions 9-14)

Las siguientes seis declaraciones a continuación (preguntas de la 9-14) representan las aspiraciones e ideales sobre cómo debería ser generalmente el material de instrucción en línea. En relación con su experiencia usando plataformas en línea para aprender el idioma, ¿qué tan de acuerdo está con las siguientes declaraciones? (The next six statements below (Question 9-14), rather than specifically refer to the online Chinese paper(s) you did at AUT, they represent the aspirations and ideals as to how online instructional material should be generally. Looking back in your experience, how much do you agree with these statements?)

(9) La instrucción de aprendizaje de idiomas en línea debe basarse en tareas en lugar de aprender de memoria. (Online language learning instruction should be task-based rather than rote learning).

(10) El material de aprendizaje de idiomas en línea debería ayudar a desarrollar habilidades de pensamiento crítico y resolución de problemas de la vida real. (Online language learning material should help develop real-life problem solving and critical thinking skills).

(11) A veces se deben usar materiales de aprendizaje auténticos. (Authentic learning materials should sometimes be used).

(12) Se deben alentar las iniciativas de los alumnos en lugar de que todo lo prepare y organice el profesor. Por ejemplo, teniendo algunas actividades de aprendizaje sugeridos por los alumnos. (Learner 
initiatives should be encouraged rather than everything prepared and spoon-fed by the teacher, e.g., having some topics of learning suggested by learners).

(13) Se debe alentar a los estudiantes a que construyan en conjunto con el profesor los recursos de la clase y el entorno de aprendizaje, y que creen en conjunto con el educador nuevos aprendizajes y conocimientos. (Learners should be encouraged to co-construct class resources and the learning environment, and cocreate new learning and knowledge).

(14) Se debe alentar la creatividad del alumno. (Learner creativity should be encouraged).

Estilos de aprendizaje (preguntas desde la 15-19)

Learning strategies (Questions 15-19)

(15) Sin una sala de clases y la presencia de un profesor, descubrí que el aprendizaje en línea es más autodirigido y autorregulado. (Without a classroom and the presence of a teacher, I found online learning to be more self-directed and self-regulated).

(16) El aprendizaje en línea es individualizado o personalizado. Permite flexibilidad, fomenta la autodirección y la elección. Por ejemplo, no siempre seguí las instrucciones del profesor o pude reorganizar el material de aprendizaje, o elegir mis propias herramientas en línea, y configurar el entorno de aprendizaje para que se adaptara mejor a mi objetivos y necesidades de aprendizaje. (Online learning is individualized or personalized learning. It allows flexibility, encourages self-direction and choice, e.g., I did not always just follow the teacher's instructions, or I was able to re-arrange learning material, or choose my own online tools, and configure the learning environment to best suit my learning goals and needs).

(17) Creo que otros miembros de la clase también formaron sus propios entornos personales de aprendizaje. (I believe other class members formed their own personal learning environments too).

(18) El aprendizaje en línea sirvió de mejor forma a mis preferencias, necesidades, vida social, opciones tecnológicas, etc. (My preferences, needs, social life, technology choices, etc. were better served by online learning).

(19) Sentí que tenía control sobre el proceso de aprendizaje. (I felt that I had control over the learning process). 